\title{
CASE REPORT OF IMPENDING RUPTURE OF LONG STANDING VENTRAL INCISIONAL HERNIA
}

Sree Ramulu P. N¹, D. Srinivasan², Sangmesh³ ${ }^{3}$, Harish Kumar', Prasanth K. Dhannur ${ }^{5}$

\section{HOW TO CITE THIS ARTICLE:}

Sree Ramulu P. N, D. Srinivasan, Sangmesh, Harish Kumar, Prasanth K. Dhannur. "Case Report of Impending Rupture of Long Standing Ventral Incisional Hernia". Journal of Evolution of Medical and Dental Sciences 2014; Vol. 3, Issue 30, July 28; Page: 8453-8456, DOI: 10.14260/jemds/2014/3069

ABSTRACT: The incidence of incisional abdominal hernia depends on many factors including old age, sex, obesity, bowel surgery, suture type, chest infection, abdominal distension and wound infection. Repair with tissue flap.

KEYWORDS: Incisional Hernia, factors, age, obesity, Bowel surgery suture type, chest infection.

INTRODUCTION: Incisional hernias develop in 3.8-11.5\% of cases after abdominal surgery. The incidence depends on a number of factors including old age, sex, obesity, bowel surgery, suture type, chest infection, abdominal distension and wound infection.1,2 Ninety percent of incisional hernias occur within 3 years of operation. ${ }^{3}$ Repair of large abdominal incisional hernias is a difficult surgical problem with recurrence being a common complication. Recurrence rates of up to $33 \%$ after first repair and $58 \%$ after second repair have been reported. ${ }^{4}$

CASE REPORT: A35 years old woman presented at out institute in the Surgery department, she had an operation 14 years ago - elsewhere - L.S.C.S for intra uterine death of the fetus and at the stay of the hospital at this time as she had troubles with her surgical wound and she had repeated secondary sutures. The hernia is in the infra umbilical midline region, has a smooth surface, shows expansible impulse on coughing, there are some dilated veins on its surface, there is no tenderness, it has a uniform consistency, mobile, there are no pulsations, it contains small intestine, partially reducible, the defect is about $10 \mathrm{cmx} 14 \mathrm{cms}$ in diameter visible intestinal peristalsis visible with Debi cutis ulcer and the skin is thinned out. Fig. 1.

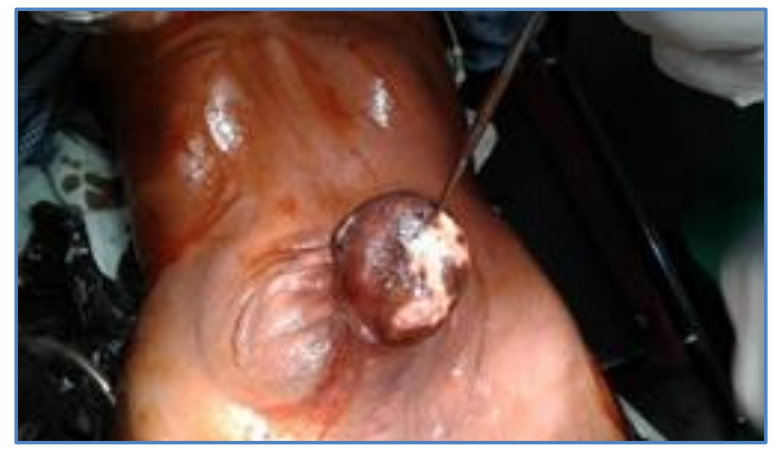

Fig. 1: hernia with Debi cutis ulcer, intestinal obstruction 
Figure 2: After releasing the adherent intestinal content the tissue flap is created of the stretched rectus abdominis muscle.

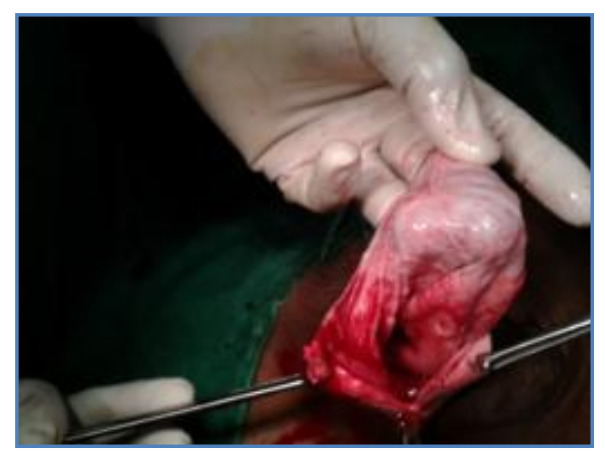

\section{Figure 2}

Figure 3: Double - double breasted. Four flaps of the stretched rectus muscle were created and folded one over and the defect in the anterior abdominal wall was re-enforced without using the Mesh.

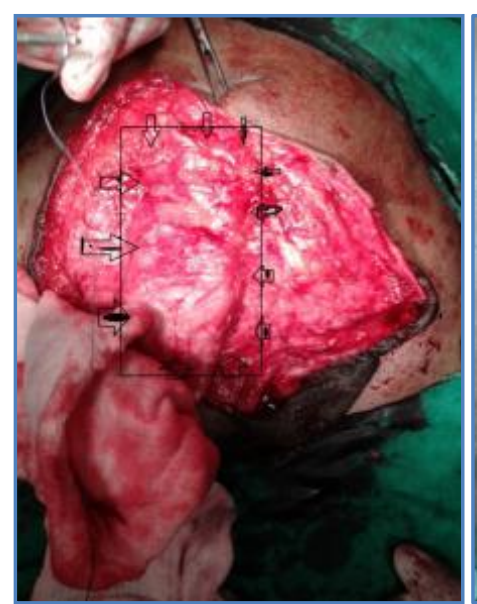

Figure 3

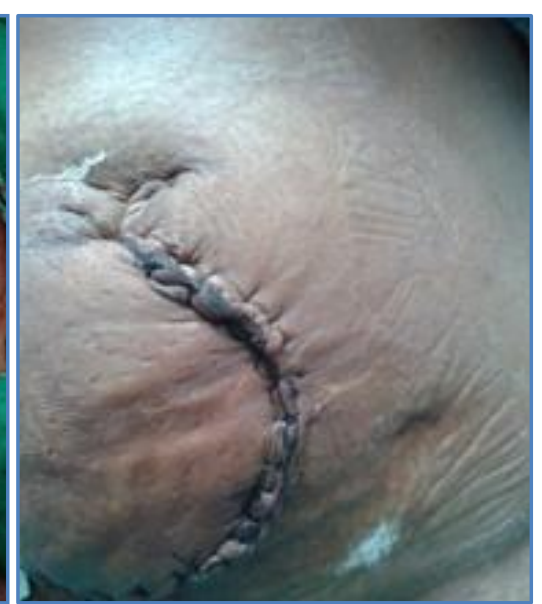

Figure 4: Final out come

DISCUSSION: In as many as 1 in 3 abdominal wall closures, the fascial layer of the wound will fail to heal due to hemodynamic instability of wound contamination, especially in malnourished patients. ${ }^{5}$ As a result, approximately 200, 000 incisional hernia repairs are performed each year in the United States alone at a financial cost of nearly 2.5 billion dollars. 6,7

Nearly 4 million abdominal and pelvic operations performed each year in the United States, it is estimated that another 200, 000 incisional hernias may be going unrecognized or untreated. Incisional hernias occur as the result of combined biomechanical failure in an acute fascial wound when considering the clinically relevant impediments to acute tissue repair together with the normal function of the abdominal wall to support increasing loads during the postoperative recovery period. ${ }^{8}$ 
Acute fascial separation occurs early in the postoperative period, leading to the delayed clinical development of abdominal wall incisional hernias. ${ }^{9}$

This phenomena occurs early in the trajectory of acute wound healing at a time when wound tensile strength is very low or absent (postoperative days 0-30). This occurs as during the earliest period of acute wound healing that the wound depends entirely on suture integrity to maintain abdominal wall closure. Simultaneously, most patients are recovering from their procedures and returning to increased levels of activity and placing increasing loads across the acute wound during its weakest phase. The most frequently identified clinical risk factors include a suboptimal closure technique, deep wound infections, malnutrition, peri-operative hypotension, steroid use, and aortic aneurysm disease. $5,10,11$

Normally, an acute fascial wound needs to pass through a complex series of wellorchestrated molecular and cellular events beginning with hemostasis and inflammation and leading through angiogenesis and fibroplasia until a provisional matrix is formed that is capable of resisting the distractive forces of the abdominal wall. ${ }^{12}$

The end point of acute wound healing therefore is the nearest approximation of normal uninjured tissue structure and function. In the case of the abdominal wall, this means the timely reestablishment of an efficient load-bearing scar at the myofascial layer. Abnormal progression of the acute wound-healing trajectory impairs the recovery of wound tensile strength. 13

The mechanism of incisional hernia formation is most often attributed to early mechanical wound failure as a result of either to the pulling through of suture passed through adjacent wound tissue, too loose or too-tight suture placement, or suture failure all occurring at a time when wound tensile strength is essentially zero. ${ }^{8}$

The use of different combinations of composite (polypropylene and e-PTFE) or resorb able prosthetic materials, of mesh with hydrophilic coatings and of mesh coupled with flaps can provide a solution, even in cases of abundant loss of abdominal wall substance, when adequate covering of the inner surface cannot be achieved with peritoneum or omentum.14,15

CONCLUSION: Incisional hernia is a very common complication of wound healing after surgery. Good care and precautions are very important to avoid its development.

\section{REFERENCES:}

1. Bucknell TE, Cox PJ, Ellis H. Burst abdomen and incisional hernia: a prospective study of 1129 major laparotomies. BMJ 1982, 284: 931-933.

2. Derek AD, Xue W, Ann K, Martin CR, Michael GF. The Prevention of Incisional Hernia Formation Using a Delayed-Release Polymer of Basic Fibroblast Growth Factor. Ann Surg 2004, 240(1): 179-186.

3. Read RC, Yoder G. Recent trends in the management of incisional herniation. Arch Surg 1989, 124: 485-488.

4. Luijendijik RW, Hop WCJ, Tol MP. A comparison of suture repair with mesh repair for incisional hernia. N Engl J Med 2000, 343: 392-398.

5. Carlson MA. Acute wound failure. Wound healing. Surg Clin North Am 2001, 77: 607-635.

6. Wedbush Morgan Securities: Biotechnology in wound care. 2001, 4: 1-82. 
7. Franz MG, Kuhn MA, Nguyen K. Early biomechanical wound failure: a mechanism for ventral incisional hernia formation. Wound Rep Reg 2001, 9: 140-141.

8. Pollock AV, Evans M. Early prediction of late incisional hernias. Br J Surg 1989, 76: 953954.

9. Viidik A, Gottrup F. Mechanics of healing soft tissue wounds. In Frontiers in Biomechanics. Edited by Schmidt-Schonbein G, Woo S, Zweifach B. New York: Springer; 1986: 263.

10. Anthony T, Bergen PC, Kim LT, Henderson M, Fahey T, Rege RV, Turnage RH. Factors affecting recurrence following incisional herniorrhaphy. World J Surg 2000, 24.

11. DuBay DA Franz MG. The Biology of wound healing failure. Surg Clin North Am 2002.

12. Franz MG, Robson MC. The use of the wound healing trajectory as an outcome determinant for acuter wound healing. Wound repair Regan 2001, 8: 511-516.

13. Deligiannidis N, Papavasiliou I, Sapalidis K, Kesisoglou I, Papavramidis S, Gamvros O. The use of three different mesh materials in the treatment of abdominal wall defects. Hernia'6(2)51-52.

14. van't Riet M, de Vos van Steenwijk PJ, Bonthuis F, Marquet RL, Steyerberg EW, Jeekel J, Bonjer HJ. Prevention of adhesion to prosthetic mesh: comparison of different barriers using an incisional hernia model. Ann Surg 2003, 237: 123-8.

15. DuBay DA, Franz MG. The biology of acute wound healing failure. Surg Clin North Am 2002.

16. Franz MG, Robson MC. The use of the wound healing trajectory as an outcome Determinant for acute wound healing. Wound repair Regan 2001, 8; 511-516.

\section{AUTHORS:}

1. Sree Ramulu P. N.

2. D. Srinivasan

3. Sangmesh

4. Harish Kumar

5. Prasanth K. Dhannur

\section{PARTICULARS OF CONTRIBUTORS:}

1. Professor, Department of Surgery, Sree Devaraj Urs Academy of Higher Education Research, Kolar, Karnataka.

2. Assistant Professor, Department of Surgery, Sree Devaraj Urs Academy of Higher Education Research, Kolar, Karnataka.

3. Assistant Professor, Department of Surgery, Sree Devaraj Urs Academy of Higher Education Research, Kolar, Karnataka.

4. Junior Resident, Department of Surgery, Sree Devaraj Urs Academy of Higher Education Research, Kolar, Karnataka.
5. Junior Resident, Department of Surgery, Sree Devaraj Urs Academy of Higher Education Research, Kolar, Karnataka.

\section{NAME ADDRESS EMAIL ID OF THE CORRESPONDING AUTHOR:}

Dr. Srinivasan, Assistant Professor, SDUAHER, Kolar-563101, Karnataka.

Email: drsrinivasandorai@gmail.com

Date of Submission: 24/06/2014. Date of Peer Review: 25/06/2014. Date of Acceptance: 18/07/2014. Date of Publishing: 24/07/2014. 